\title{
A ausência de fora e a recusa da catástrofe: crise ambiental e destituição dos dualismos
}

\author{
Pedro Sobrino Laureano ${ }^{\star}$ \\ Universidade Federal de São João Del-Rei, São João del Rei, MG, Brasil
}

\begin{abstract}
Resumo
Pretende-se, neste artigo, discutir a atual crise do meio ambiente a partir da ideia desenvolvida por Antonio Negri e Michael Hardt de que, no capitalismo contemporâneo, "não há mais fora". Buscamos apresentar algumas ideias que permitem entrever, dentro da atual conjuntura, o delineamento de uma ética e uma política baseadas na constatação de que, ao perdemos a ideia da natureza como espaço exterior intocado pela história, perdemos algo que nunca existiu. E que tal perda constitui um índice apenas negativo de um movimento de reconfiguração das categorias políticas modernas que não são mais capazes de pensar a crise global, não apenas do capitalismo, mas também do próprio meio ambiente.
\end{abstract}

Palavras-chave: capitalismo; crise ambiental; inconsciente; fora.

\section{The absence of outside and the refusal of the disaster: environmental crisis and dismissal of dualisms}

\section{Resume}

We intend to discuss, in this article, the capitalist and environmental crises of today's world based on the idea, developed by Antonio Negri and Michael Hardt, that "there's no outside" of today's capitalism. We seek to develop some ideas that can contribute to think, in the current conjuture, the sckatches of an ethics and a politics based on the afirmation that, when we lose the idea of nature as na outside untouched by history, we lose something que that has never existed. And also that this lost constitutes only an negative index of a necessary movement of questioning the modern political categories that are no longer able to think the global crisis, not only of capitalism, but also of the environment.

Keywords: capitalism; environmental crisis; unconscious; outside.

Atualmente, vivemos os choques de duas crises concomitantes e indissociáveis: a capitalista e a ambiental. A primeira diz respeito à subjetividade, ou seja, a nossas formas de desejar, se relacionar, produzir. A segunda é consequência da primeira. A racionalidade econômica do capitalismo contemporâneo-aquele que Marx (2010) anteviu como da subsunção real e Antonio Negri e Michael Hardt (2000) denominam Império - teria nos levado ao limiar da catástrofe, ou seja, da extinção da espécie humana.

Buscaremos desenvolver algumas direções éticas e políticas que, em nossa opinião, podem resistir ao perigo do "catastrofismo", sem contudo "negar" a possibilidade da catástrofe. Há mais de duas décadas Deleuze e Guattari (1996[1980], p. 108) já diziam: “a situação atual é desesperadora”. Entretanto, pensamos, que este desespero - sentimento talvez demasiadamente psicológico - quando transformado em necessidade e abertura, pode transmutar-se em ação política radicalmente não voluntarista, que tem na crise da imagem antropológica do "homem" uma de suas vias de constituição fundamentais.

\section{Subsunção formal e real}

Comentando a ascensão do capitalismo contemporâneo, no livro Pós-modernismo: a lógica cultural do capitalismo tardio, o filósofo norte americano Fredrik Jameson (1997, p. 102) afirma que "o pós-modernismo é o que se obtém quando o processo de modernização e a natureza desaparecem para sempre". Jameson refere-se à

Endereço para correspondência: Pontifícia Universidade Católica do Rio de Janeiro - Departamento de Psicologia. Rua Marquês de São Vicente, 225, Sala 201L. CEP. 22453-900. Gávea, Rio de Janeiro - RJ.E-mail: pedro@laureanopsi.com.br crise daqueles espaços que, na modernidade, ainda constituíam "exteriores absolutos" em relação ao ocidente europeu. São, segundo Jameson, outros povos e culturas não ocidentais, contudo, mais profundamente, a própria natureza e o inconsciente. Na representação moderna, a natureza ainda continha elementos insubmissos à sua apreensão pela razão instrumental, e o inconsciente era a continuação, dentro do homem, desta natureza indomada, insubordinável.

O filósofo segue as teses de Marx que, nos Grundrisse (2010) e no Capital (2011) aponta como tendência interna do capitalismo a subsunção "real" do planeta. Buscando resolver suas contradições, entre a produção coletiva e a apropriação privada, a superacumulação e o subconsumo, o capital tem, necessariamente, que tornar-se global: se expandir por todas as esferas da produção, para além das fronteiras territoriais. "A tendência a criar o mercado mundial está imediatamente dada no próprio conceito de capital. Cada limite aparece como uma barreira a ser superada" (MARX, 2010, p. 332).

Marx nos diz que, na subsunção ainda "formal", o capital aproveita-se de forças e relações de produção já existentes. Situa historicamente este momento como o da acumulação primitiva, na Inglaterra do século XVII. É quando as terras comuns (commons) cultivadas por camponeses são cercadas. Grande parte da população, que dependia do cultivo do solo para a sobrevivência, é força- 
da a migrar para os centros urbanos, num fenômeno que contribuirá para a expansão dos grandes centros comerciais Ingleses, como Birmingham e Londres.

A subsunção formal, então, integra os elementos da produção que já se encontram presentes na sociedade. São os saberes centenários acumulados por artesões, manufaturas, famílias, camponeses... Com o tempo, o capital apodera-se por completo do ciclo produtivo, submetendo as relações de produção e as forças produtivas ao seu único imperativo, o da expansão econômica ilimitada. Trata-se, segundo Marx, da subsunção real: a relação capitalista já não é uma força estranha e violenta, vinda de fora, mas naturaliza-se, passando a constituir o horizonte subjetivo e produtivo da existência social.

A necessidade de desenvolvimento tecnológico e da racionalidade administrativa transformam as relações de produção. A acumulação abstrata, representada pela famosa fórmula marxiana, D-M-D+ (dinheiro compra a mercadoria para, sem seguida, transformar-se em mais dinheiro), substitui o modo de produção das sociedades pré-modernas, ainda pautado pela satisfação das necessidades e pelo consumo do valor de uso, ao final do ciclo da troca.

$\mathrm{Na}$ fórmula D-M-D+, "o valor aparece como sujeito" (Marx, 2011, p.243): causa primeira e final do ciclo produtivo. Ele já não é mais "meio" de troca entre duas mercadorias qualitativamente diversas, mas são as próprias mercadorias que se tornam elementos subordinados à expansão do valor. $\mathrm{O}$ valor de uso é capturado nesta operação simbólica que consiste em "sublimar" a "necessidade" biológica de satisfação em "demanda" social de produção. Trata-se da demanda de que o valor cresça infinitamente, traçando uma linha virtual de expansão que independe de "contratempos" sociais ou ambientais.

A lógica da racionalidade capitalista mostra-se absolutamente irracional, quando se trata da distribuição social da riqueza e da relação com o meio ambiente. Ela busca sujeitar qualquer valor extrínseco ao da expansão econômica. Igualdade, liberdade e fraternidade, certamente, mas também a natureza, como valor comum, commonwhealth dos homens. O indivíduo privado que acumula torna-se o grande modelo antropológico a ser reproduzido.

No limite, como nos diz Jameson (1997), a própria natureza e o "inconsciente" - a natureza em nós, se seguirmos a definição freudiana de inconsciente (FREUD, 2006) - devem ser "colonizados". Ou seja, a subsunção real não significa apenas um aumento extensivo dos limites territoriais do capital, mas uma mudança qualitativa na forma de organização do sistema. Nossos desejos inconscientes passam a ser peça integrante e solicitada pela máquina de acumulação.

\section{"Não há mais fora"}

Este passagem por Marx e pela teoria da subsunção foi necessária para que retomemos estas teses de Jameson. Trata-se, então, desta constatação da "colonização" do inconsciente e da natureza pelo capitalismo de nossos tempos, o da subsunção real. Os antigos espaços de exterioridade radical, aqueles que se colocavam como "lados de fora" em relação à matriz antropológica do homem
Europeu, teriam sido definitivamente integrados. Mas será que o termo "colonização" é realmente pertinente, na atual conjuntura? Como falar em colonização se, justamente, não encontramos mais uma alteridade absoluta que poderia ser colonizada?

Para compreendermos as características da integração capitalista na atual fase de subsunção real, podemos nos utilizar de uma tese desenvolvida por Antonio Negri e Michael Hardt (2000, p. 208), segundo a qual, no mundo de hoje, "não há mais fora". Trata-se da constatação, pelos autores, de que o tempo do imperialismo, dos diversos estados-nação em concorrência pela hegemonia financeira, territorial e militar do planeta, teria terminado. O imperialismo seria característico da fase histórica da subsunção formal, aonde ainda havia territórios radicalmente exteriores ao capitalismo Europeu. O que temos, agora, é a modulação contínua de fronteiras e territórios, de mercadorias e pessoas, "dentro de um mesmo mundo", integrado dentro do que Negri e Hardt denominam Império. Não há então colonização, já que não há propriamente, "um lado de fora para ser colonizado".

Mas como resistir, neste mundo onde a subsunção real parece colocar-nos diante de um quadro asfixiante de dominação? Seria necessário procurar por uma nova categoria de alteridade ou de exterioridade, buscando outra base por meio da qual poderíamos criticar a globalização capitalista? Se respondermos afirmativamente a esta questão, de fato, a situação atual nos parecerá desesperadora, e seremos obrigados a caracterizar o presente a partir da ideia de falta, ou de negatividade. De maneira que inexoravelmente nos depararemos com a falta deste lugar de exterioridade através do qual articular o espaço para a transformação, seja que o chamemos "natureza" ou "inconsciente", como vimos com Jameson, mas também "revolução", "socialismo", "proletariado", conforme articulado pela tradição marxista.

Segundo esta hipótese, na falta desta categoria de exterioridade, nossa época seria caracterizada por aquilo que o filósofo francês Françoise Zourabichvili (2000) chamou de "esgotamento dos possíveis". Mas, ao contrário de Zourabichvili, que pensa tal esgotamento como a condição necessária da transformação política, estaríamos diante apenas da constatação de um défict, de maneira que apenas nos restaria aguardar pelo retorno a uma política "verdadeiramente" subversiva. Isto é, de uma política capaz de desenhar o espaço da subversão através da ideia mesma de uma verdade que se desdobraria para além do jogo de simulacros e aparências que caracterizam o capitalismo tardio. Estaríamos inevitavelmente condenados a realizar o luto da exterioridade, e aguardar pelo ressurgimento do próprio campo da verdade como sendo o campo por excelência da política.

De fato, o esgotamento dos possíveis pode ser lido não apenas como o tornar-se artificial ou o tornar-se simulacro da natureza e do inconsciente, e da consequente crise dos espaços do fora, mas também através da constatação retroativa de que este espaço de exterioridade, que supostamente forneceria a verdade através da qual se criticar a fantasmagoria dos simulacros e aparências sociais, "nunca 
existiu". Subitamente, é como a tese empírica ou apenas sociológica a respeito do desaparecimento de uma natureza bruta não mediada pelo trabalho humano, ou do inconsciente como espaço de exterioridade em relação à moral ou à cultura, se desdobrasse em uma tese ontológica. Não apenas descobrimos que em nossa época tais espaços de exterioridade parecem cada vez mais reintegrados, paulatinamente fadados ao desaparecimento, mas, mais fundamentalmente, descobrimos que "eles nunca existiram".

Tal redobramento do empírico no ontológico, de uma tese sociológica a respeito do capitalismo tardio em uma tese ontológica a respeito do estatuto do fora e de oposições como aquelas entre interior e exterior, natureza e civilização, inconsciente e consciente, nos parece constituir o movimento capaz de construir um novo problema apto a questionar o niilismo inerente à constatação de que as categorias modernas que informaram o espaço de resistência já não comparecem, no cenário contemporâneo. É esta passagem de uma constatação sociológica a uma tese ontológica, de fato, que nos parece apta a transformar o movimento negativo da crise do fora no movimento de constituição de um novo horizonte no qual é justamente a ausência absoluta do fora que se torna fundamental na determinação do acontecimento político.

De maneira que constatamos que aquilo que chamávamos de natureza já era, nela mesma, um constructo artificial, "independente da mediação histórica do trabalho humano"; assim como o inconsciente não é o espaço da verdade do sujeito, o núcleo do recalcado que poderia ser acessado através da crítica das ilusões da consciência, mas já é nele mesmo simulacro, máscara, artifício ou, como o pensa Deleuze (2006[1968]), diferença. Neste sentido, não basta constatar a perda das referências exteriores, mas constatar que, paradoxalmente, nunca tivemos aquilo que perdemos.

Por mais paradoxal que possa parecer, portanto, é em ideias como a de "esgotamento dos possíveis", desenvolvida por Zourabichvilli (2000), e na crítica da ideia de exterioridade que fundamentava os movimentos de resistência modernos, que podemos buscar uma resposta à crise capitalista e ambiental. Pois constatar que no contexto contemporâneo os possíveis estão esgotados e que, por isto, não há mais um fora ao qual recorrer para se articular a oposição em relação ao "dentro" do poder significa que, como argumentam Deleuze e Guattari (1996[1980], p. 94) em Mil Platôs,

[...] uma sociedade se define por suas linhas de fuga, que são moleculares. Sempre vaza ou foge alguma coisa [...] aquilo que se atribui a uma "evolução dos costumes", os jovens, as mulheres, os loucos, etc.

Isto é, a resistência não pode ser mais representada como um bloco exterior que negaria o estado de coisas atual. Não há ancoragem transcendente que permita discernir um movimento universal de contestação justamente porque a contestação, a resistência, as fissuras que atravessam o poder, são absolutamente imanentes ao próprio poder. São "linhas de fuga" que não desenham uma exterioridade em relação a um interior, mas um mo- vimento absolutamente imanente daquilo que Deleuze chamou de "devir revolucionário" (DELEUZE, 1992, p. 211). A resistência não apenas está por toda parte, como é "primeira", constitui o dado ontológico fundamental através do que podemos escapar às representações globais do dentro e do fora, do exterior e do interior.

$\mathrm{O}$ que se delineia através da ideia de recusa do fora é, justamente, a recusa do antropomorfismo moderno. Pois é justamente através da fundamentação antropomórfica da política que foi desenhado o espaço do Outro como, por exemplo, a própria ideia de natureza, ou de inconsciente. E, sendo assim, assentar neste Outro as esperanças por uma categoria não contaminada pela lógica moderna já é, de antemão, habitar o espaço conceitual daquilo que se quer criticar.

Em As palavras e as coisas, Foucault (1964) chama a atenção para o fato de que categorias caras à psicanálise e ao estruturalismo, como aquelas de inconsciente, se buscaram pensar o espaço da alteridade radical em relação ao humanismo inerente aos saberes clássicos, por ainda dependerem deste mesmo humanismo, não conseguiram ultrapassar o marco conceitual em relação ao qual buscaram romper.

É por isto que, ao final do livro, afirmando que o homem era um conceito relativamente recente na história, o filósofo antecipa seu fim: "Então pode-se apostar que o homem se desvaneceria, como à beira do mar um rosto de areia" (FOUCAULT, 1964, p. 502). Para Foucault, o projeto antropológico de submissão da natureza e da constituição do homem como "império dentro de um Império" (SPINOZA, 2007[1677], p. 161), mais cedo ou mais tarde, terminaria. E o filósofo pedia, portanto, uma nova forma de pensamento apta a destituir, não apenas as categorias antropológicas, mas também aquelas constituídas como oposição inerente a estas mesmas categorias, insuficientes ainda para, de fato, assentar o pensamento sobre novas bases.

O homem não é uma realidade última que teria sido “descoberta" pelos saberes e práticas humanistas da modernidade, mas uma produção relativamente recente de nossa cultura. Produção que não desenhava apenas este "rosto na areia" do qual fala Foucault, mas também o espaço da natureza como Outro em relação ao próprio homem. Ora, o que vemos hoje na subsunção real é que, se talvez a ideia de uma natureza que já não seja artifício ou mediada pela cultura foi definitivamente apagada, tal "rosto de areia" que constituiu para Foucault a constituição do antropomorfismo moderno ainda persiste. E, na falta daquele ponto de ancoragem exterior que constituía o fora, ficamos órfãos de formas de atuação política capazes de contestar o poder atual.

Daí a dificuldade de se articular um projeto de contestação radical capaz de escapar a certo pressentimento catastrofista que parece ser inerente a uma época na qual a crise das políticas baseadas na ideia de fora ou de exterioridade parecem ressoar junto à crise capitalista $\mathrm{e} a \mathrm{da}$ própria natureza. É como se assistíssemos impotentes ao desdobramento de três crises correlatas, justamente porque o horizonte que nos permitia articular o espaço da crítica já não mais existe, porém ainda não assumimos as 
novas categorias capazes de repensar uma política para uma época na qual "não há mais fora". Ora, é justamente esta política que autores como Deleuze, Guattari, Antonio Negri e Michael Hardt, buscam pensar.

\section{Resistências}

Criticar o capitalismo em seu potencial destrutivo, que hoje que ameaça destruir a espécie humana é, ética e politicamente, necessário. Obviamente, todos que acompanham com um mínimo de seriedade as discussões científicas sabem que, como espécie, corremos perigo. Alguns dizem que o desastre já teria ocorrido, ou seja, que o modo como vivemos já está drasticamente solapado pelas transformações climáticas impostas pelo capital e pelo produtivismo de nossos tempos. ${ }^{1} \mathrm{O}$ projeto antropológico naufragou no oceano do aquecimento global.

Não queremos duvidar de tais constatações. Pelo contrário, dada à seriedade política, cientifica e filosófica (as três estão interconectadas) daqueles que nos lançam estes alarmes, ouvimos atentos, ficamos consternados. Mas será que a catástrofe nos autoriza uma ética do "catastrofismo"? A catástrofe "objetiva", embora gerada por fatores subjetivos, deve ser subjetivamente assumida como "limite" simbólico e físico do humano?

De fato, descartando todas as concepções teológicas a respeito de uma providência divina, que teria dado ao homem o papel intermediário entre a natureza bruta e o Ser transcendente, sabemos que o homem é parte da natureza. Como tal, ele encontra-se inevitavelmente sujeito à ação de outras causas que não àquelas que decorrem de sua própria potência de agir e de pensar. É este o argumento que Spinoza defendeu, há mais de quatro séculos, em sua Ética (2007[1677], p. 269): sempre há, no universo infinito, uma causa mais forte capaz de superar a nossa, em potência.

A razão nos leva a concluir que uma catástrofe realmente poderia ocorrer, "a qualquer momento, independente" dos fatores humanos envolvidas em sua determinação. Ainda que passemos a entreter com a natureza e com os outros uma relação de não exploração, que consigamos destituir o projeto megalomaníaco do capitalismo atual, criando democracias reais, deixando de explorar o trabalho alheio, derrubando as hierarquias que nos estriam em classes, raças, etc., poderia ser que, “ainda assim”, um asteroide caísse sobre nossas cabeças.

Hipótese de ficção científica? Não, se lembrarmos de que o fato de não sermos, como espécie, seres especiais, nos lança em um universo alheio; universo que é, segundo Deleuze (2006[1968]), ao mesmo tempo, "indiferente e radicalmente diferencial". Tanto mais diferencial e descentrado quanto mais indiferente é ao nosso destino enquanto espécie. O universo natural que "somos" é mais próximo, de fato, aos relatos de ficção científica do que às imagens apaziguadoras de um todo harmônico e integrado.

Dentro deste marco radicalmente não teleológico, nossa tarefa não é mais a de lamentar a inversão dialética do projeto do Homem naquele da extinção do ho-

Tais pesquisas e cientistas podem ser encontrados na edição especial da revista Nature Climate Change, de setembro de 2009, online. mem, mas a de "radicalizar o anti-humanismo dentro de uma política radicalmente 'pós'- humana". Uma ética da alteridade na qual os outros não sejam apenas os "indivíduos" por intermédio dos quais aprendemos a nos reconhecer. Trata-se, então, de uma alteridade absolutamente "radical" em relação àquilo que somos. Alteridade aonde a natureza não seria mais um fora, seja para ser conquistado ou, então, usado como alavanca para se pensar uma exterioridade radical de onde partiria a contestação, mas uma "diferença absoluta" capaz de nos descentralizar de nosso suposto lugar de mestria.

É esta tese que Deleuze e Guattari (2010[1973]) defendem quando argumentam, em $O$ anti-Édipo, que natureza e cultura apenas podem ser pensadas por meio de um processo de desterritorialização mútua. Trata-se de um movimento de dupla diferenciação em que a oposição entre natureza e cultura é destituída: a natureza torna-se insubmissa às imagens da ciência e da filosofia clássicas, que a caracteriza como sistema mecânico de causa e efeitos, contraposto ao homem enquanto ser livre, estranho ao mundo natural. Tornam-se, ambos, natureza e subjetividade, diferenças, singularidades dentro do mesmo plano geo-histórico (DELEUZE; GUATTARI, 1992).

Isto nos leva a propor certas modulações da tese de Negri e Hardt (2000), segundo a qual no capitalismo da subsunção real e do Império não haveria mais fora. É que tal tese deve ser lida junto a sua complementação inerente, a de que, se não há mais fora, igualmente "não há mais dentro". Não há totalidade que produza, como sua exclusão interna, um fora como negação, a partir da qual o todo mesmo se constitui. Ora, estes eram os casos, certamente, não apenas de categorias como as de natureza e de inconsciente, mas também de todos aqueles Outros da razão moderna que, erigidos em oposição ao império do Mesmo, terminaram por determinar a inversão não apenas teórica, mas também histórica, da diferença em identidade, e da identidade em diferença. A tese defendida por Negri e Hardt de que não há mais fora significa que não perdemos, no contexto contemporâneo, apenas o fora, mas também o todo ou o dentro a partir do qual o fora poderia ser construído.

De fato, toda a obra e a intensa atividade política de Antonio Negri e Michael Hardt, a contínua participação e teorização da resistência e a valorização dos movimentos de resistência históricos e contemporâneos mostram que não se trata de anunciar a dominação absoluta e escatológica do capitalismo imperial. Pelo contrário, o que interessa a estes autores é mostrar como no cenário atual, após a crise das políticas modernas de contestação, assentadas na ideia de exterioridade radical, a única forma de resistir ao catastrofismo aparentemente inerente à ideia de que "não há mais fora" é através da elaboração de uma política radicalmente imanente. Comentando a ascensão do Império e descartando qualquer postura catastrofista, os autores salientam: "Abandonem os sonhos de pureza política [...] que nos permitiriam continuar fora! Tal reconhecimento niilista, [...] deve ser um ponto de passagem em direção a um projeto ético alternativo. [...]" (NEGRI; HARDT, 2009, p. VII). 
"Não há mais fora" é, então, apenas a constatação de que não há mais uma alternativa "transcendente" pela qual se lutar. E que, se a esquerda contemporânea limitar-se a lamentar a crise das alternativas utópicas, ela se tornará incapaz de acompanhar as oportunidades abertas, mesmo na fase crítica em que vivemos. A captura, pelo capitalismo contemporâneo, da geografia, do inconsciente e da natureza, significa apenas que a exterioridade "já era" produzida pela própria máquina dual que se encarrega de circunscrever, de antemão, o espaço da resistência, tornando-o dependente daquilo em relação ao qual ele resistia. De maneira que a pergunta correta, no contexto atual, é: como podemos pensar, através do cenário de crise do fora, a constituição de uma política assentada em bases radicalmente distintas das modernas?

O livro $O$ anti-Édipo, de Deleuze e Guattari (2010[1973]), representou uma das tentativas fundamentais de se articular uma política não mais assentada sobre a máquina de dualismos constituída pela modernidade. E um dos conceitos fundamentais construídos pelos autores é aquele de "máquina desejante" (DELEUZE; GUATTARI, 2010[1973], p. 81). Trata-se da produção ininterrupta que a natureza, tendo o homem como parte comum e imanente, realiza. Uma produção que não obedece a qualquer critério finalista, a qualquer necessidade biológica de sobrevivência, mas ao que biólogos como Humberto Maturana e Francisco Varela (1980) chamam de autopoiese: a capacidade que os organismos possuem, como sistemas abertos, de se reinventarem incessantemente.

Tal invenção implica, necessariamente, no questionamento das fronteiras entre exterior e interior, na destituição da ideia do organismo como uma totalidade fechada em si mesma, que deveria se adaptar a um ambiente já constituído. Pelo contrário, a capacidade fundamental do organismo, para Maturana e Varela, é não apenas aquela de transformar o próprio meio, mas também a de, transformando o exterior, alterar a si mesmo. Interior e exterior não constituem mais fronteiras absolutas, limites inquestionáveis, mas modulações imanentes de uma mesma natureza cuja determinação fundamental é aquela da transformação perpétua.

Ora, o capitalismo atual define-se justamente pela tentativa de se apropriar desta potência bio-histórica que Deleuze e Guattari buscaram pensar através do conceito de máquinas desejantes, próximo àquilo que Maturana e Varela chamaram de autopoiese. O capitalismo, de fato, não mais reparte uma alteridade absoluta em relação à qual ele se opõe, buscando reprimi-la exteriormente. Ele agora "modula" a cooperação múltipla e plural dos indivíduos e da natureza. Tudo é permitido: não mais importa nacionalidade, etnia, sexualidade e o caráter dos indivíduos que produzem, mas apenas a capacidade destes de se constituírem como geradores de valor.

É desta forma, então, que o capitalismo parece circunscrever radicalmente o espaço do fora, integrando incessantemente o exterior ao interior, dissolvendo os limites e assentando a produção sobre o imperativo de expansão ininterrupta. O próprio conceito de inconsciente, tal como proposto por Freud (2006[1930]), já não parece ter mais a carga crítica de outrora, torna-se plenamente integrável no funcionamento de um capitalismo capaz de assimilar a sexualidade como meio para a valorização do valor. E, da mesma maneira, a natureza também nos parece previsível e calculável, ao ponto em que não se torna apenas possível prever nossa própria extinção, mas também assistirmos, atônitos e impotentes, o desenrolar de uma lógica social que sabemos acarretar na possibilidade de extinção.

Entretanto, como temos argumentado a partir de Negri e Hardt, diante deste quadro de integração aparentemente absoluta, o mais fundamental é abandonar o sonho de um fora a partir da constatação de que, se não há fora, é porque também não há mais dentro. De maneira que a ideia de uma dominação global do capital, que constituiu uma das bases através da qual Marx pôde elaborar o conceito de subsunção real da sociedade no capital, e à qual corresponderia uma suposta "falência da crítica" (SAFATLE, 2008), deve ser questionada. Pois se há, de fato, uma falência da crítica, é porque a crítica, perdendo os espaços de exterioridade a partir dos quais poderia criticar o capitalismo, deixou-se reduzir à constatação de que a lógica do capital, em sua fase atual, é absoluta, ou apenas questionável a partir de um evento pensado como exterioridade capaz de ressuscitar a base clássica que constituía o Outro do homem moderno.

$\mathrm{Na}$ verdade, os dois movimentos são indissociáveis. A imagem do capitalismo como máquina totalizante, por um lado, e a ideia de uma intervenção exterior capaz de cancelar seu automatismo cego, por outro, confluem na ética de resignação que eleva a catástrofe e o luto, a nostalgia do antigo e a ausência de futuro, em horizonte político máximo. A crítica do fora deve ser capaz, justamente, de responder ao porquê de, no cenário atual, esperamos a intervenção ex-nihilo de um evento capaz de resistir a uma dominação pensada como absoluta.

Se adotarmos a tese de Deleuze (2006[1968]) de que o homem é parte imanente da natureza, vemos que ambos, natureza e homem, não constituem a imagem que lhe conferimos habitualmente, tornando impossível qualquer ideia de totalização. A natureza não é uma sucessão mecânica de causas e efeitos, e não é apenas no homem que devemos buscar a ideia de liberdade. Para Deleuze, a natureza e o homem habitam um só e mesmo plano de imanência (DELEUZE; GUATTARI, 1992), mas tal plano é atravessado por um movimento de diferenciação interna que torna impossível a constituição de qualquer totalização capaz de saturar a cadeia de causas e efeitos dentro de um universo fechado. Impossível integrá-los dentro de qualquer racionalidade abstrata, ainda que modulatória, como no caso do atual capitalismo.

A capacidade de criar desvios, bifurcações em relação à ordem não constitui, portanto, uma prerrogativa humana, mas um movimento ontológico que atravessa a oposição entre natureza e cultura. Se uma das categorias principais que são mobilizadas, dentro da crise ecológica atual, é aquela da ética como devendo respeitar os limites da razão humana, o fato de que a natureza constitui um espaço de radical exterioridade que confronta o sujeito com 
sua finitude radical, pensamos que tal ética é, portanto, incapaz de pensar a natureza não enquanto lugar da exterioridade ou da finitude, mas enquanto processo de diferenciação. De fato, parte da filosofia ocidental se pautou na consciência da finitude para distinguir o homem dos demais animais, e da natureza em geral; pensamos, entretanto, que não é recaindo nestas velhas aporias e crises da razão que poderíamos dar algum sentido à experiência contemporânea, por mais terrível que ela nos pareça ser.

Trata-se de repetir o gesto de Deleuze quando, em Lógica do sentido (2007[1969]) escreve a respeito do "acontecimento". A ideia de acontecimento, em Deleuze, é oposta àquela de uma intervenção ex-nihilo que poderia suspender a causalidade empírica ou natural, a de um "milagre" capaz de instituir o espaço do fora e conferir um sentido transcendente para as contradições do presente. Pelo contrário, o acontecimento, para o filósofo, implica antes na constatação de que não há nada além das causas e efeitos corporais, de que o sentido imaterial que emerge do plano material é absolutamente imanente à própria natureza. E que é justamente por não haver nada fora da causalidade natural que está radicalmente descentrada, diferencial: não encontrado ponto de ancoragem exterior a partir do qual será avaliada, a causalidade não se torna um princípio de ordenação capaz de colmatar as transformações imanentes à matéria, mas um processo de diferenciação imanente, sem telos ou história, sem origem ou finalidade.

Isto é, o acontecimento implica apenas em uma mudança de ponto de vista, através da qual destituímos à causalidade corporal a ideia de transcendência, ou de "falta". Neste sentido, o acontecimento é impassível, indiferente ao bem e ao mal, ao prazer ou ao desprazer, etc.: ele apenas afirma aquilo que acontece. Em relação, tanto à ausência de fora quanto à crise ambiental atual trata-se, portanto, de se perder as categorias antropológicas que constituem a avaliação "humana" dos eventos, e afirmar o acontecimento como sentido imanente ao estado de coisas do mundo (ou do "fim de mundo"). Apenas assim, segundo a lógica do sentido de Deleuze, seriamos capazes de transmutar a dor em sentido, o negativo em uma ideia de afirmação capaz de transformar a crise em uma nova forma de vida, ou naquilo que Nietzsche (1999[1887]) chamava de "transvaloração de todos os valores".

No contexto político que vivemos, tal ideia de acontecimento significa que a tripla crise, do capitalismo, das categorias usuais que informam os movimentos de contestação históricos e também da própria natureza, relaciona-se àquele movimento de "esgotamento dos possíveis" que Zourabichvili apontou como constituindo o movimento essencial da política. Não se trata mais, portanto, do lamento ou do luto pelo fora perdido, mas de uma política que nasce do ocaso dos valores transcendentes que informavam a política moderna e da constituição de uma política radicalmente imanente.

Podemos lembrar, aqui, do exemplo do compositor francês Oliver Messiaen que, numa prisão nazista quando da ocupação da França pela Alemanha, compôs e tocou, com os instrumentos precários de que dispunha no cárcere, o Quarteto para o fim dos tempos: o fim dos tempos não nos desautoriza a afirmar o acontecimento. Pelo contrário, "ele eleva tal afirmação a um ato necessário". Não mais a afirmação do artista diletante ou do "voluntarismo" de uma militância política composta por palavras de ordem ou clichês, mas a criação que Zourabichvili (2000) chamou de involuntária: o espasmo de invenção que acomete um corpo destituído de sua capacidade em organizar-se enquanto organismo, a produção da imanência como potência de um corpo moribundo que se afirma para além de sua constituição orgânica.

No contexto contemporâneo, trata-se de pensar a constituição de uma política que reconheça na ausência de fora também a ausência de um dentro, a partir do qual o fora se organizaria; isto é, a ausência de qualquer totalização global do poder que autorize, às sombras sinistras da catástrofe "objetiva", uma ética pautada no lamento do ocaso das velhas categorias da crítica. Justamente de categorias tais como fora e dentro, ou como as de natureza e cultura, portanto.

Ante à possibilidade de extinção, portanto, talvez a postura ética mais justa seja aquela de enxergar na crise a urgência de uma nova forma de fazer político irredutível às imagens usuais do dentro e do fora, da natureza e da cultura. Forma na qual tanto o homem como a natureza não constituam mais a face cômoda que adquiriram aos serem pensados enquanto opostos, mas possam tornar-se, neles mesmos, radicalmente singulares. De maneira que possa ser recusada não apenas a ideia da "razão instrumental" humana em seu papel de dominação da natureza, "mas também a de uma natureza harmônica que haveria sido corrompida pela cultura". Paradoxalmente, é porque a natureza nunca foi uma exterioridade passiva que poderia ser oposta ao terreno da atividade humana que se torna, hoje, necessário relacionar a crise das categorias políticas moderas com a crise da própria natureza. Diante dos "possíveis" da catástrofe, trata-se de pensar a "necessidade" de uma nova constituição política.

\section{Referências}

DELEUZE, G. Diferença e repetição (1968). Rio de Janeiro: Graal, 2006.

DELeUZE, G. A lógica do sentido (1969). São Paulo: Perspectivas, 2007.

DELEUZE, G. Conversações. Rio de Janeiro: Editora 34, 1992.

DELEUZE, G.; GUATTARI, F. $O$ anti-Édipo (1973). São Paulo: Editora 34, 2010.

DeleuZE, G.; GUATTARI, F. Mil Platôs: capitalismo e esquizofrenia (1980). São Paulo, Editora 34, 1996. v. 3.

DELEUZE, G.; GUATTARI, F. O que é a filosofia? Rio de Janeiro: Editora 34, 1992.

FOUCAULT, M. As palavras e as coisas. Lisboa: Portugalia, 1964.

FREUD, S. O mal-estar na civilização (1930). In: SALOMÃO, J. (Org.). Obras Psicológicas Completas de Sigmund Freud. Rio de Janeiro: Imago, 2006. v. XIX, p. 73-150.

Fractal, Rev. Psicol., v. 27 - n. 2, p. 123-129, 2015 
JAMESON, F. Pós-modernismo: a lógica cultural do capitalismo tardio. São Paulo: Ática, 1997.

MATURANA, H.; VARELA, F. J. Autopoiesis and cognition: the organization of the living. Boston: Reidel, 1980.

MARX, K. Grundrisse. Rio de Janeiro: Boitempo, 2010.

MARX, K. O Capital: crítica da economia política (1867). Rio de Janeiro: Civilização Brasileira, 2011. livro 1.

NATURE CLIMATE CHANGE. [Online]: Nature Publishing Group, set. 2009. Disponível em: <http:/www.nature.com/ nclimate/archive/issue.$h t m l$ year $=2009 \&$ month $=09 \#$ sectioneditorial>. Acesso em: 28 ago. 2012.

NEGRI, A.; HARDT, M. Império. Rio de Janeiro: Record, 2000 .

NEGRI, A.; HARDT, M. Commonwhealth. Harvard: The Belknap Press of Harvard University Press, 2009.

NIETZSCHE, F. A genealogia da moral (1887). São Paulo: Companhia das Letras, 1999.

ZOURABICHVILLI, F. Deleuze e o possível (sobre o involuntarismo na política). In: ALLIEZ, E. (Org.). Gilles Deleuze: uma vida filosófica. São Paulo: Editora 34, 2000. p. 333-356.

SAFATLE, V. Cinismo e falência da crítica. São Paulo: Boitempo, 2008.

SPINOZA, B. Ética (1677). Belo Horizonte: Autentica, 2007.

Recebido em: 11 de setembro de 2012 Aceito em: 13 de janeiro de 2015 